\title{
A Qualitative Study on Managing Millennial Mindsets: Awaiting Challenges for HR Strategists and Recruiters
}

\author{
Prof Dr. C. Karthikeyan, \\ Director-ASB, MBA Department, \\ Adithya Institute of Technology, Coimbatore, Affiliated to Anna University, \\ Chennai, Tamil Nadu, \\ India
}

\begin{abstract}
Millennials are children born between 1980 and before 1995 (considered as of now) who are now in the industrial scenario as new age work force after Generation X. Their parents focus on giving a stable sustainable personal growth structure by planning every activity since their school and encourage to take risks to learn and adhere to required demands of new digital world. They possess very high self-esteem and know or aware of the world that is fuelled with technology. Millennial never believe statements saying that the world was not having the digital devices like computers, network protocols, digital transformation of information and networked world. They absolutely fit for the high tech digital connectivity in the world and wiered of sentiments in work culture. Any new normal situations in the world of work is simple for them to understand and more career oriented than a loyal employee for the organisation whats so ever the organisation promises or delivers or holds a brand name. They keep moving on and sustaining even for a limited period is going to be a big challenge for organisations in time to come. Any Strategic HR policies how ever immune are to be tested in time to come. Success of organisations will be dictated by these millennial mindsets.
\end{abstract}

\section{Keywords}

Millennials, Mindsets, Employee Engament,Flexible, Digital savvy, Career Oriented

\section{INTRODUCTION}

The Millennials are a new generation, a new employee, a new trend, a big challenge. Leaders of organisations and HR managers who used certain practices to extract the best out of employees, is not going to work now, those days are gone. The upcoming employees are "different than you and me" according to F.Scott Fitzgerald. Human Resource strategists and managers who used practices like employe engaging methods of yesteryears are to change their ways due to the upcoming challenges posed by the millennials. If the managers want to engage them and they need to make the millennials feel wanted and respected. Every employer is aware of the current challenges of employee engagement and talent retention, whether big or small company. The engagement policies are coming in for a challenge. The millennia generation commonly known as Gen-Y and includes births from $1982-2000$ are growing in the workforce and baby boomers are retiring. HR professionals from all sectors now is in the pressing need to take note of the generational differences, in attitude, behaviour, acceptance of orders and instructions and loyalty. HR professionals now need to have a really challenging HR talent retention strategies and dynamic engagement models. Numerous characteristics as simple as talking style, dress code etc that differentiate millennials from other generations, is going to pose a totally different challenge or even a threat to HR Strategies for retaining sustainable strategies for their organisations. The Millennials a new generation with a new set of engagement priorities : Millennials who were born between 1980 and before 1995 (though this date range is up for debate), came into the work scenario after Generation X, who are lucky to have parents who had focus on their growth. They grew up with people concerned that they have high self-esteem, and they are also where you will find your first true digital natives, those individuals who have no memory of what life was like without computers and the internet. Human Resource Managers accustomed to using employee engagement tactics and retention strategies or policies are challenged or removed or at least re-modified. These organizations which can't address creative employee engagement policy needs to become dynamic and prepare workforce policies which are challenging, interesting, innovative and more so on digital platforms. Research from across the globe has addressed that this upcoming generation looks for flat management structures and teamwork-based job roles. Millennials in particular have a typical different outlook, their aspirations and convent educated, digital savvy, computer and high speed networking ability with multi-skilled nature is giving a very different message to HR professionals to senior level policy makers of employers a very tough time.

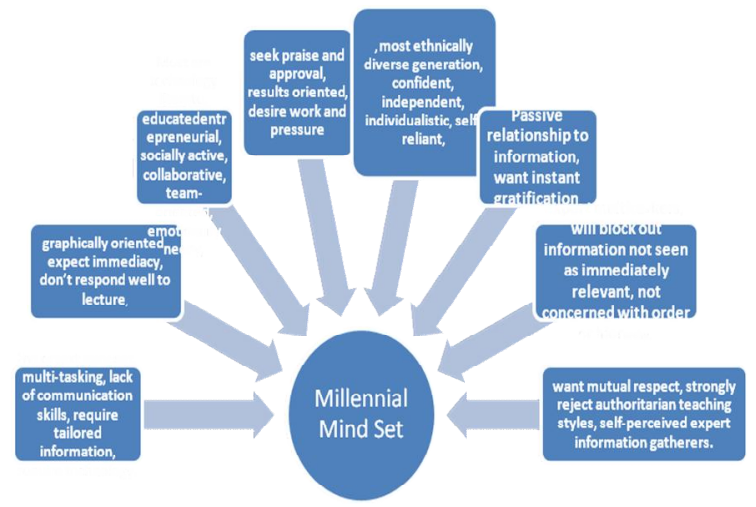

Figure 1: Graphical Display- Characteristics of Millennial Mindsets; Conceptualised from Literature Review of Shaw \& Fairhurst(2008), Berge (2008); Graph Concept; Author Dr.C.Karthikeyan.

2. Millennias are very self-confident, able to multi-task, and have plenty of energy. They have high expectations for 
themselves, and prefer to work in teams, rather than as individuals. Millennials wants challenges, and gives importance for work life balance and express higher level need for social interaction, immediate results in their work, and desire for speedy advancement. These all may be seen as weaknesses by older colleagues, but that has no impact on the millennial generation, and they are emerging as the largest age group to emerge since the baby boom generation, and as this group grows significantly as a proportion of the workforce over the next 20 years, employers will need to make major adjustments in their engagement models. Motivating, engaging, and retaining people will never cease as managerial priorities, but employers will have to carefully consider what strategies they will use to cultivate and retain valuable millennial employees now and into the future?

\subsection{Objectives}

(i) To understand the Milliennial Mindsets and their Expectations in Corportates.

(ii) To evaluate the lessons learned from existing practices in talent retention versus the upcoming challenges in retaining the Millennials.

(iii) To learn the Milliennial Mindsets Expectations and Attitude towards work.

(iv) To examine the leadership strategies adopted to counter the challenges posed by Milliennials

\subsection{Methodology}

Qualitative Analysis using literature and secondary data of authorised sources like Delloite Studies

\subsection{Scope of the Study}

Contribution HR strategies and Talent Retention Challenges for the HR managers.

\section{REVIEW OF LITERATURE}

Berge (2008) Hypertext mindset, multi-tasking, lack of communication skills, graphically oriented, expect immediacy, don't respond well to lecture, require tailored information, require technology.

Shaw \& Fairhurst (2008) Most are technology literate, educated, most ethnically diverse generation, confident, independent, individualistic, self-reliant, entrepreneurial, socially active, collaborative, team-oriented, emotionally needy, seek praise and approval, results oriented, desire work and pressure, high external locus of control, high maintenance, value institutional learning, rapidly assimilate information, active learners.

Meister \& Willyerd (2010) Attention sponges, need constant feedback, in a hurry for success, view work as a key part of life, want a personally fulfilling life, have high expectations of themselves and others, committed to community service, academic overachievers, live a mobile, collaborative, and immediate lifestyle.

Bohl (2008) Passive relationship to information, want instant gratification, expert multitaskers, will block out information not seen as immediately relevant, not concerned with order or hierarchy, want mutual respect, strongly reject authoritarian teaching styles, self-perceived expert information gatherers.

Twenge, Campbell, Hoffman, \& Lance (2010) Technologically savvy, like informality, learn quickly, embrace diversity, need supervision Spring 2014 Volume 12, Number 1 Journal of Organizational Learning and Leadership.
Skiba \& Barton (2006) Digital natives, fiercely independent, open about emotions and intelligence, inclusive, express views freely (often strong views), innovative, preoccupied with maturity, investigative, desire immediacy, sensitive to interests of others (especially employers), authenticate before trusting, close to parents, value intelligence, need group activities, multi-taskers, first person learners.

Gorman, Nelson, \& Glassman (2004) Strong written communication skills, work collaboratively, gather information quickly, share information readily, respect diversity, value multiculturalism, resilient, easily converse with adults regarding intellectual topics (without reservation), may struggle if unsupervised.

Monaco \& Martin (2007) Lack professional boundaries, entitled, lack critical thinking skills, unrealistic expectations, desire a "how to" guide for success, want to invest as little time/effort as possible to achieve success, think of themselves as special \& winners, sheltered by parents, team-oriented, confident, highly optimistic, multi-taskers, desire immediacy, pressured, achievers, conventional.

Wesner \& Miller (2008) Most educated generation, Equate more education to more opportunities, selfconfident, embrace new technology, mobile, multi-taskers, not concerned with loyalty to employer, achievement-minded, want to contribute tangibly, desire meaningful work Donnison (2010) Confident, optimistic, self-assured, high self-esteem, informed, knowledgeable, experienced consumers, ambitious, success-oriented, goalachieving, over confident of employability, skills and abilities, collaborative.

Wilson \& Gerber (2008) Special, sheltered, confident, teamoriented, achieving, pressured, conventional Elam, Stratton, \& Gibson (2007) Hard working, extracurricular-focused, generous, practical, structured, goal achievement-minded, assessmentoriented, team-oriented, socially networked, close to parents, stunted interpersonal skills, possible lack of critical thinking skills, respectful, conventionally motivated, responsible, conscientious, structured rule-followers, protected, sheltered, cooperative, mutually inclusive, talented achievers, confident, optimistic Glass (2007) Patriotic, benefitted from technology, socially minded, confident, teamoriented, structured, high selfesteem, results-oriented, constant feedback.

Partridge \& Hallam (2006) Achievers, team-oriented, strong emphasis on family, society and community oriented, collaborative attitude, Work to live - don't live to work, pragmatic but optimistic, involved, tolerant, sheltered, structured, seek support, technologically savvy, desire constant stimulation, valued education, motivated, desire quick answers, multi-taskers, active learners.

Objective (i): To understand their Expectations in working life: Where the Millennials expect at work : Most of the research suggests that, Millennials are working more in teams and use more technology. Their social mindset, however, is also a significant factor. As Leigh Buchanon writes in Meet the Millennials, "One of the characteristics of millennials, is they are more digital and thrive to give back and being civically engaged are their highest priorities." They are creative and are growing up in a time where any information is available instantly with just a click of a mouse. With Google or Wikipedia search, any answers to even quite complicated questions are available. The millennial employee is interested in correct and professional feedback on his or her performance and finds semi-annual reviews too infrequent. They just are keen to know that they've done a good job, 
instantly. A 2008 article in Nonprofit World provides readers with a checklist on the topic of providing millennial feedback. The list includes: give them checklists, offer plenty of help, reward them for innovating and taking appropriate risks, engage them with frequent feedback, provide them with mentors, create a collegial and team-oriented culture, etc.
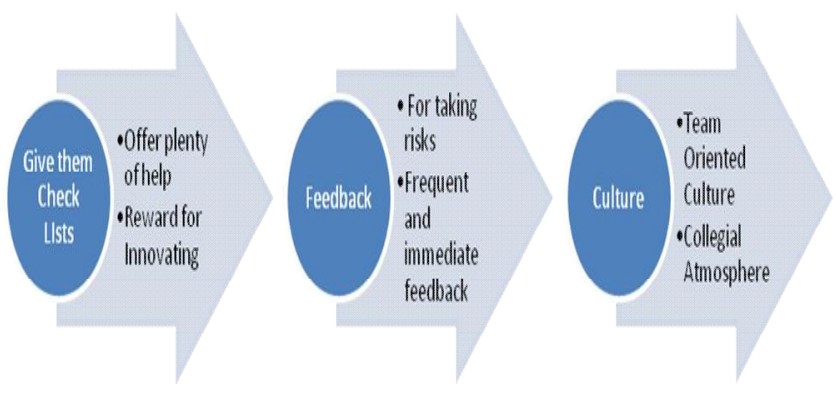

Figure 2: Graphical Representation for Objective 1 from the concept of "expectations in work setting by the Millennials: Concept from “don't be so touchy" Joanne Sujanski's article. Concept designed by Author; Dr.C.Karthikeyan

Feedback must also be given in such a way that millennials are receptive. Not only are the timing and frequency important, but so too is the way in which feedback is framed and delivered. In Joanne Sujanski's article "Don't be so touchy! - The secret to giving feedback to millennials," she writes, "Instead of feeling appreciated, however, the few short accolades of "good job" were overshadowed in the employee's mind by the more frequent criticisms he received - without guidance as to how exactly he could improve." (SuperVision, December 2009). Sujanski reaches an insightful conclusion: Whether positive or negative, feedback needs to be structured in a way that leaves no room for misunderstanding. Feedback needs to be clear and specific to be effective.

\subsection{The Challenges of Engagement Strategies for Millennials; from Corporate Perspective}

Creating successful engagement strategies to engage millennials requires two main thoughts in mind throughout. First, are millennial engagement needs different from other generation? And second, which engagement drivers are appropriate? About 3,500 millennial and baby boomer respondents of six companies, with 10 qualitative interviews, the conclusions are that generational differences do exist between millennials and baby boomers. As the social characteristics of the generations differ, it seemed plausible at the outset that the ways in which employees become satisfied with their work and bring both their bodies and their minds to work every day would be different. In pushing these findings further and into practice, employers should adopt the belief that to sustain prolonged engagement, they must understand carefully manage the engagement drivers and threats. As part of the outputs from "Managing Performance" and "Career Opportunities" the most important engagement drivers according to the study are "Employer Reputation" and "Managing Performance" were viewed as the most important engagement threats. Karthikeyan C (2017)(qualitative data from secondary source for this study) In the interviews, participants shared the following observations on their engagement experience with employers.

- Motivate and engage or manage employee engagement on a micro scale.

- Millennials with less than 5 years experience are eager to learn and develop, and are flexible to change.

- Train and retain top talent and with providing multiple opportunities including business development, challenging/interesting engagements and international assignments.

- Feedback even quite negative feedback, needs to be given as and when and millennials are open in knowing what the expectations are and how they can stack up.

Engagement is a measure where inputs vary in the overall engagement equation across organizations. One company cannot necessarily imitate the engagement practices or use the engagement variables of another to achieve success. The job of managers and human resources professionals responsible for engagement is to know that there are generational differences, and that the engagement drivers for their company will not always be the same as their leading competitor, business partner, or parent company. By buying into this notion, leaders should begin conversations in their own organizations in pushing to learn which drivers they can adjust to increase engagement, and which drivers they must protect to prevent decreases in engagement across generations.

Objective (ii); to evaluate the lessons learned from existing practices for retaining talent vis a vis the upcoming challenges: From the researches done so far generational gaps do exist. The results reveal the presence of employee engagement differences across generations. The gaps are due to companies indicate which drivers are more likely to become high priority for employees (managing performance, recognition, career opportunities). It is obvious from the learning from various research contribution that having an engagement strategy is not enough. When using engagement the study insists that focus should be on intrinsic motivation in the company above before People / HR Practices. A key challenge that will linger around are equitable across generations, but still demands of millennials surpass the current generation. Managing performance is the most indispensible of with feedback on the performance without any periodically generated reports, but should there be a timing (without delay), frequency (often), and way in which feedback is delivered (clear and specific) is what is very indispensible for the millennials. This stands as the most important priority of this organizational process is essential in managing engagement. Employer reputation is the most frequent engagement when perceptions of employer reputations decrease, a similar decrease in engagement spreads throughout the workforce. This finding is profound; engaged employees are emotionally attached to their organizations, and when employer reputation changes, so do relationships of employees with employers, specifically by the millennials. Managing engagement; Engagement is becoming more important than ever and talent retention can act as a key competitive advantage for businesses over the coming years. With the high costs of employee turnover, peaking at up to 150 percent of the employee's annual salary, engagement and retention initiatives done properly will have a significant impact on an organization. 


\subsection{Identify Key Engagement Drivers and Threats That Most Significantly Impact Workforces}

Employers should be benchmarking themselves against these drivers, which will act as the key metrics for monitoring. Set appropriate targets and goals for your engagement strategy. Goal-setting exercises must be properly designed in order to develop reasonable targets. There are multiple ways to think about setting targets. Implications for employees must be considered when deciding which approach to use. The three key drivers are have multiple strategies that have a meaningful impact on engagement. Employees across generations should become more engaged, and will hopefully notice the commitment their employers have made in improving their employee experience. Assigning engagement champions which shall be a key role, and shall be responsible to collect and share information from across the organization relating to engagement. In large organizations, this role will be an important communication channel that spreads news, results, ideas, and feedback. Giving proper discretion to managers to reward and recognize when appropriate and execution of the strategy is just as important as having the strategy itself, as employees' engagement levels are the result the strategy. Does environment dictate mindset; Research shows that Millennials desire to live without any disturbance and highly value privacy (what they know) vs. Nurture (where it's more of an adaptiveness to the environment), the one thing that sticks out range from survival to fully embracing the opportunity. It's the latter that separates everyone from the rest.

Objective (iii); to learn the cultural implications the Milliennial Mindsets have created in recent times in corporate working culture:

What happens with marketing culture due to influence of Millennial Mindsets; Does that mean marketers target a mindset... NOT a generation?; Jure Klepic, a research and marketing professional, who specializes in consumer and cultural insights, the purchase decision is so complex that "Consumer Mindset for the Modern Brand," will dominate the workforce in less than a decade becomes the focus for many marketers. Ross Quintana says based on demographics, geography, ethnicity, marketers need to think differently and age should not be the differentiator. Generational stereotypes are just what it means to have a Millennial Mindset. What Gen Z's Arrival In The Workforce Means For Recruiters; Generation Z's arrival in the workforce means some changes are on the horizon for recruiters. This cohort, born roughly from the mid-90s to approximately 2010, will be entering the workforce in four short years, and you can bet recruiters and employers are already paying close attention to them. Flexible schedules will continue to grow in importance; With the growth of part-time and contract workers, unlike Millennials, Gen $\mathrm{Z}$ came of age during difficult economic times; older Millennials were raised in the boom years. As Alex Williams points out in his recent New York Times piece, there's an argument to be made thatGeneration $\mathrm{Z}$ is similar in attitude to the Silent Generation, growing up in a time of recession means they are more pragmatic and skeptical than their slightly older peers. We don't have all the answers; With its youngest members not yet in double digits, Gen $\mathrm{Z}$ is still maturing. There is obviously still a lot that we don't know. This generation may have the opposite experience from the Millennials before them, where the older members experienced the booming economy, with some even getting a career foothold, before the collapse in 2008. "To recruit in this environment is like being part wizard, part astronaut, part diplomat, part guidance counselor," and that's very true. How The Digital Economy Is Defining An Entire Generation it's just the economy. Everything we do happens in the abstract digital economy - we shop digitally, get our news digitally, communicate digitally, and we take pictures digitally. In fact, the things that we don't do digitally are few and far between. Millennial disruption in the digital economy fastmoving, highly technical era, innovation and technology are ubiquitous, forcing companies to deliver immediate value to consumers. This principle is ingrained in Millennials view. Millennial leaders of the emerging (digital) economy as scrappy, agile, and comfortable making decisions that disrupt the norm, and that may or may not pan out.

What does it take to earn the attention of Millennials? Here are three things you should consider: Millennials appreciate innovations that reinvent product delivery and service to make life better and simpler. Uber, Vimeo, ASOS, and Apple are some of the most successful disruptors in the current digital economy with already a mature market and used technology to make valuable connections with their Millennial customers the companies were forced to reinvent the way business is done within the economy. It's not technology that captures us - it's the simplicity that technology enables: Recently, McKinsey \& Company revealed that "CEOs expect $15 \%-50 \%$ of the companies' future earnings to come from disruptive technology." Considering this statistic, it may come as a surprise to these executives that buzzwords - including cloud, diversity, innovation, the Internet of Things, and future of work does not resonate with or unique to Millennials. Making daily activities simpler with the use of technology has been seen throughout history and Millennials just happen to be the first generation to be completely reliant on technology, simplicity, and digitally powered "personal" connections. Millennials harp on technology revolution easily and digital revolution evolving as a fact of life, companies like SAP, Amazon, and Apple were able to create a new digital future. So the new gen organizations need to develop easy-to-use, brilliantly designed products, market them effectively to the masses, and maintain their product elite. It's not easy, but the companies that upend an entire industry are successfully balancing these tasks. Disruption is the new normal for millennials; digital reality, anyone, anywhere, at any time can cause disruption and bring an idea to life. With the creation of SAP S/4HANA, disrupting the tech market in digital transformation, removing data warehousing and enabling realtime operations, companies are reimagining their future.

\section{TOP TEN STRATEGIC TRENDS}

These are the top 10 strategic trends Gartner sees breaking out of the emerging space to have a potentially substantial impact over consumers and industries during the next five years. UPCOMING TOP 10 STRATEGIC TRENDS

\subsection{Artificial Intelligence (Ai) and Advanced Machine Learning}

Including deep learning, neural networks, and natural-language processing, will move beyond traditional rule-based algorithms to create systems that understand, learn, predict, adapt, and potentially operate autonomously. This is what makes smart machines appear "intelligent." 


\subsection{Intelligent Apps}

Like VPAs (virtual personal assistants) and VCAs (virtual customer assistants) have the potential to transform the nature of work, as well as sales and customer service, performing some of the functions of people and making everyday tasks easier and more efficient.

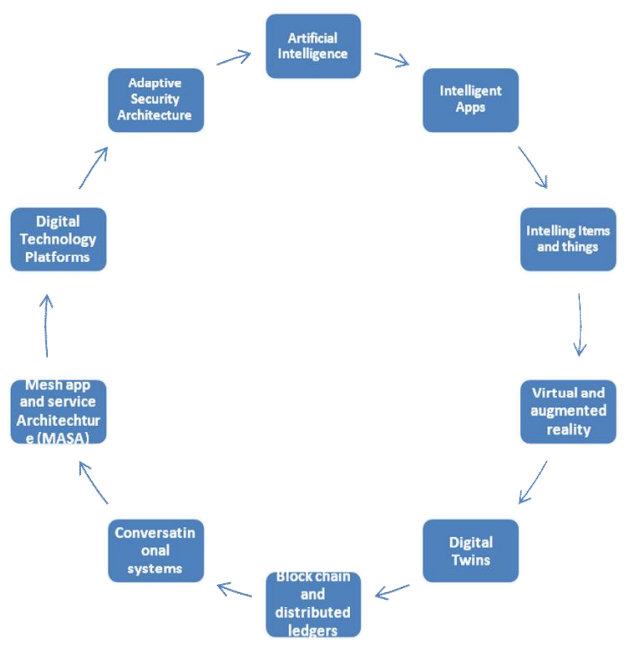

Figure 3: The upcoming Top 10 Strategic Trends "concept of Gartner" that millennials will create for next 10 yrs. Graphic Concept ; Author Dr.C.Karthikeyan

\subsection{Intelligent Things}

like drones, autonomous vehicles, and smart appliances shift from standalone programming to a collaborative intelligent things model, exploiting applied AI and machine learning to deliver advanced behaviors and more natural interaction with their surroundings and people.

\subsection{Virtual and Augmented Reality}

Dramatically transform how people interact with each another and software systems. Get ready for hyper-personalization from relevant apps and services across multiple mobile, wearables, Internet of Things, and sensor-rich environments that extend immersive applications beyond isolated and single-person experiences.

3.5 Digital Twins, dynamic software models of a physical thing or system using sensor data to proactively improve operations and add value, will represent hundreds of millions of things within three to five years.

3.6 Block Chain and Distributed Ledgers are gaining traction because they hold the promise to transform industry operating models by adding trust in an untrusted environment. While the current hype is around the financial services industry, there are many possible applications including music distribution, identity verification, title registry, and supply chain.

\subsection{Conversational Systems}

(Think: chat bots and microphone-enabled devices) move beyond traditional desktop computers and multiple devices to encompass the full range of endpoints with which humans might interact. Gartner refers to "mesh" meaning the dynamic connection of people, processes, things, and services supporting intelligent digital ecosystems. As the device mesh evolves, connection models will expand and greater cooperative interaction between devices will emerge, creating the foundation for a new continuous and ambient digital experience.

\subsection{Mesh App and Service Architecture (MASA)}

Enables people using apps to have an optimized solution for targeted endpoints in the digital mesh (e.g., desktop, smartphone, automobile) as well as a continuous experience as they shift across these different channels.

3.9 Digital Technology Platforms provide the basic building blocks to enable digital business. Every organization will have some mix of five digital technology platforms: information systems, customer experience, analytics and intelligence, IoT, and business ecosystems.

3.10 Adaptive Security Architecture, where intelligent digital mesh and related digital technology platforms and application architectures create an ever-more-complex world for security. Beyond just keeping people from breaking in, security is adaptive and embedded into system design.

Objective (iii) ;To learn the Milliennial Mindsets Expectations and Attitude towards work. Casual Attitude; millennial's mindset; (totally opposite to gen $\mathrm{x} / \mathrm{y}$ ); The idea of a five-day-aweek 9-to-5 job is absolute. They crave for freedom till their destiny. They are building communities, mentoring each other and offering assistance and advice. They believe in networking and supporting each other's projects in the hopes of everyone attaining riches. That success doesn't come without obstacles. They are the most educated generation in history. Creating a Millennial-Savvy Product; Millennials, with their love of apps, online games, and immersive websites, also expect interactivity in their content. The challenge for content creators catering to millennials, of course, is how to include interactivity with little to no technical expertise or help. Creating more engaging content is just one part of the story. The content needs to be more accessible on mobile than ever, as millennials rely on their devices. When it comes to corporate learning, millennial employees want to access and use the content at multiple touch points on multiple devices during the day, from classroom training with a company-provided laptop to self-guided learning on their tablet at home or even quick reference on their mobile phone between meetings. To meet millennials where they already are, teams responsible for building learning content need solutions that can distribute that content to any device. The "Millennials in the Workplace" trend is here to stay; To survive and thrive, businesses are constantly re-assessing how their strategies align with new trends, and the surge of millennials in the workplace has already influenced new communication practices. The new buzzword on the block is BYOD (Bring Your Own Device) and the data is again compelling: When high-risk mobile use meets millennial demand; Nevertheless, it's dangerous to immediately convert to a new, mobile world where the ramifications of a "risk gone awry" are unknown. With the entrance of mobile, a new list of security 
concerns emerges: Who can access this content? Can they do it in off-hours? Can do they do it while out of the office? If they are terminated, do they still have access? The answer to these questions is simple: millennials are the generation of receiving information-on-demand, and finding answers to questions is a skill they have curated for years. Searching the Internet is not a new concept, and navigating the spectrum of results-be it quality sources or garbage-is also nothing new. The trick is, this generation is accustomed to finding "good enough" and then moving on. The bottom line; The tides are turning, as more millennials enter the workforce every year. The companies that adapt their tools and environments today will be a step ahead in building the leaders of tomorrow. Embracing a BYOD policy may not be right for every business-many businesses take the alternative route of issuing their own devices-but the key lies in finding a solution that both satisfies this emerging workforce, while staying grounded in your business needs. Emerging Millennial Mindsets in the Workplace; Millennial mindsets are emerging from the extended recession that has caused them to be underemployed and dealing with debt: whiners vs. winners. Millennials get upset faster and for no reason like; This generation is dealing with a challenging situation they were never properly trained for. However, as the blogging battle above points out, it's how they'll choose to deal with this adversity that will determine their fate. Whatever doesn't kill you makes you stronger. How successful you are depends on how much you're willing to put up with. Companies have to hire Millennials, with 50 percent of our work force, and within 10-15 years will make up 75 percent of the work force it is better to invest company's time and money on recruiting and retaining. Instead of management hierarchies, flat management structures are becoming the norm. Instead of the powerful individual, jobs are now teamwork-based. Instead of a lifelong career, job hopping is all the rage. So managing Millennials meant understanding a new generation, and not to forget Millennials have their own opinions on the workforce.

Objective (iv); To examine the leadership strategies adopted to counter the challenges posed by Milliennials; What researchers picturise is; The Deloitte 2015 Millennial survey revealed that this generation thought $75 \%$ of businesses were more focused on their own goals rather than on helping society (this is important, and we'll talk about this more later). According to that study, that "an organization's treatment of its employees is the most important consideration when deciding if it is a leader." To the Millennial generation, being a good leader means you must:

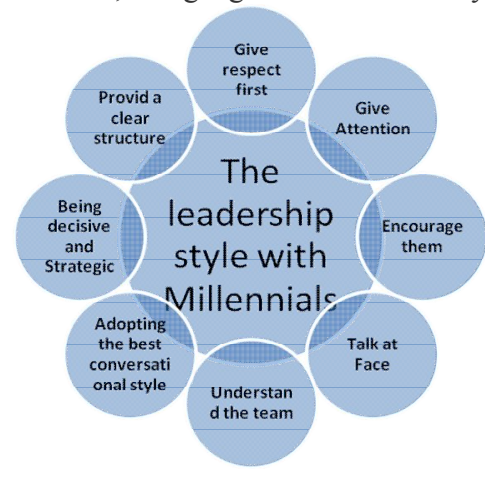

Figure 3: The expectations on a Leader by Millennials; Concept from "Delloitte 2015 survey. Graph Concept; Dr.C.Karthikeyan
- Give respect

- Give attention to them

- Don't be a wet blanket better encourage them

- Talk to them face to face

- Understand the team

- Adopt a conversational style

- Be decisive and strategic

- Provide a structure

Millennials are looking for leaders who care about people. Millennials tend to want to know why. A Millennial worker generally wants to know why you want them to do it and they examine the need to understand their place in a situation or the need to make sure the work they are doing has value. Millennials don't want to be given busy or meaningless work just to keep them occupied, they want to be sure their work matters in the larger scheme of things. They want to be given work that they feel they "own" and can run with, knowing they are making a difference.

Feedback ties into leadership ; if they need to find something, the click the search button and get instant feedback. They play video games and get a score on their performance. They send text messages, and receive quick replies. Millennials are used to feedback, which needs to include praise and constructive critique, and ties very directly into that idea that you need to lead instead of manage Millennial workers. The key to feedback, especially the constructive critique variety, is to take on the role of a coach (who inspires and encourages) instead of a taskmaster (who controls and corrects) with your Millennial workers.Maintaining work life balance; Millennials often mix personal life with work life. Millennials want to socialize and do things with their coworkers, so creating planned and regular activities in the workplace (or after hours) might fit nicely into this generational trait. They also talk about their personal lives with their team members, and may expect to talk about personal aspects of life with managers. Millennials bring their personal life into their work. However, the PwC study revealed that $71 \%$ of Millennial employees (compared to $63 \%$ of non-Millennial employees) said that work demands interfering with their personal lives was not acceptable.

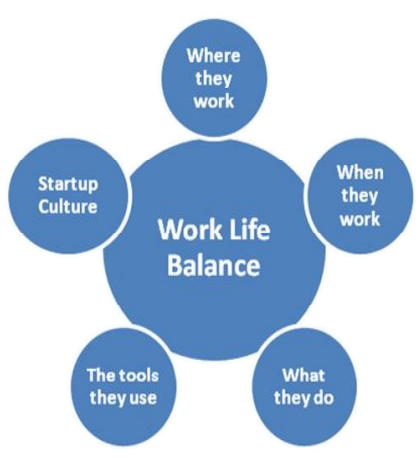

Figure 4: Work Life Balance Approach of Millennials; Concept ; PwC study report; Graph Concept; Dr C Karthikeyan

Though Millennials approach work differently than other generations, they are no less committed to getting the job done, and do not expect everything handed to them by employers. Millennials are positive-thinking with an entrepreneurial and hard-working spirit who want their lives to matter, believing they 
can change the world. They are a fantastic addition to your team, and, perhaps more importantly, a huge workforce that you will continue to rely on heavily in the future.Two-thirds of Millennials express a desire to leave their organizations by 2020 . Businesses must adjust how they nurture loyalty among Millennials or risk losing a large percentage of their workforces. Millennials Loyalty; Millennials, in general, express little loyalty to their current employers and many are planning near-term exits, according to Deloitte Touche Tohmatsu Limited's fifth annual Millennial Survey. Deloitte surveyed nearly 7,700 Millennials from 29 countries during September and October 2015 to learn more about Millennials' values and ambitions, drivers of job satisfaction, and their increasing representation in senior management teams. Two-thirds of Millennials express a desire to leave their organization by 2020. Businesses must adjust how they nurture loyalty among Millennials or risk losing a large percentage of their workforces. Two in three Millennials expect to leave by 2020

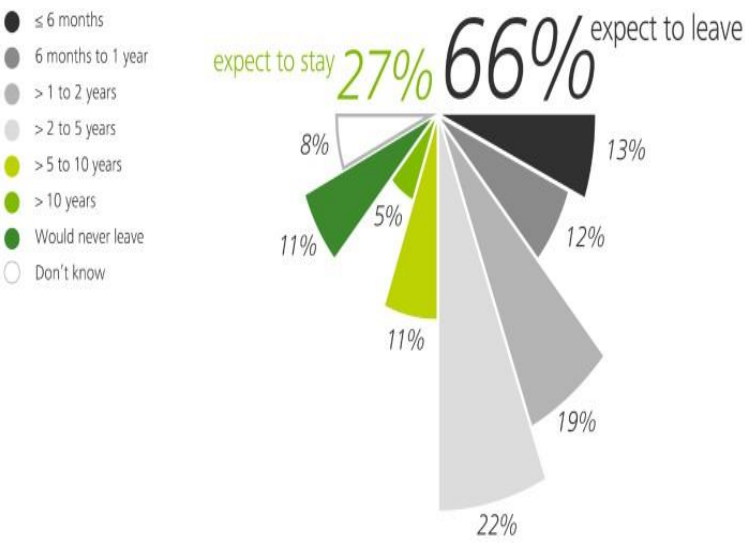

Figure 5: Source; PwC study report ;Graph; Dr.C.Karthikeyan

In each of the 29 countries where Millennials were surveyed, a majority believe they will have left their organizations before 2020 has passed. Millennials in emerging markets are the least loyal to their current organization. Percentage who expect to leave in the next five years.

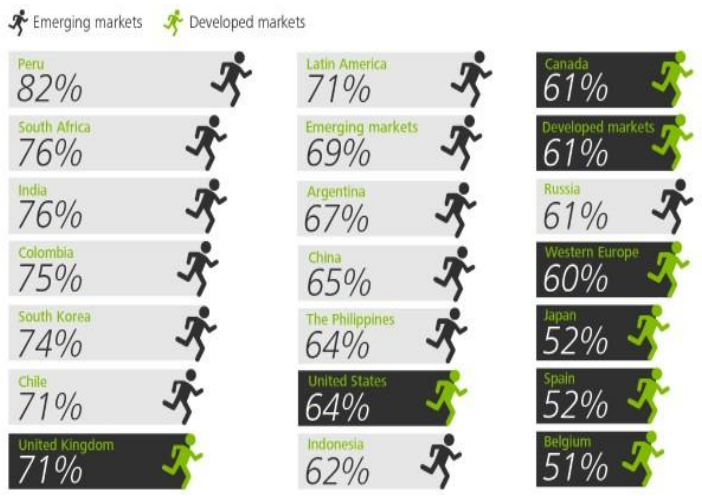

Figure 6; Emerging trends of Millenials; Source; PwC study report on milliennials

Demographic subgroups, show somewhat more loyalty than those without children; 32 percent of the former intend to remain with their current employers for five years or more, compared to 24 percent of the latter. This is a statistically significant difference. That said, twice as many (64 percent) Millennial parents expect to leave their current employers before 2021 compared to those who expect to stay beyond this date. Women (67 percent) are slightly more likely to leave within the next five years than men (64 percent). $\quad$ Lack of loyalty is due to only 28 percent of Millennials feel that their current organizations are making 'full use' of the skills they currently have to offer." Last year, when asked to rate the skills and attributes on which businesses place the most value (and are prepared to pay the highest salaries), Millennials pointed to "leadership" as being the most prized. This was mentioned by 39 percent, but only 24 percent thought this was a strong personal trait of theirs upon graduation (a gap of 15 percentage points). Millennials fully appreciate that leadership skills are important to business and recognize that, in this respect, their development may be far from complete.
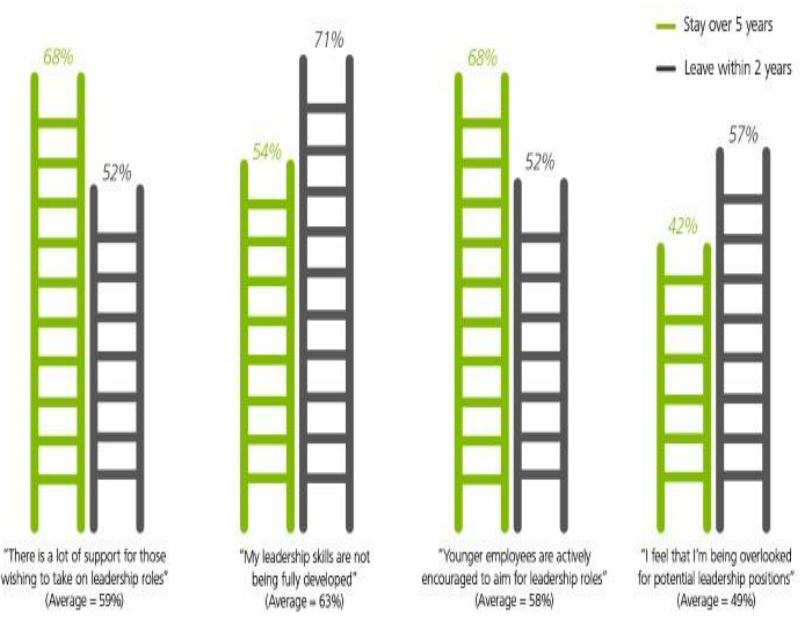

Figure 7: Source; PwC study report on Millennials

It is encouraging to report relatively small gender differences in consideration for senior roles. However, the absolute figures are disappointing - 50 percent of male and 48 percent of female

\section{Millennials Express a Desire to Leave Their Organization by 2020;}

The millennials are not impressed by the "buzz" around a business. Millennials judge the performance of a business on what it does and how it treats people. For example, among those saying business "means more than a healthy balance sheet," more than six in 10 would reference the quality of its products and services (63 percent) or levels of employee satisfaction (62 percent). A majority (55 percent) focus on customer loyalty/satisfaction. Innovation and efficiency also rank highly. Millennials are less impressed by the sheer scale of a business, its age, or the general buzz that surrounds it. Millennials very much believe that business success is built on a foundation of long-term sustainability rather than pursuing short-term profit maximization. Customer care and high-quality, reliable products also ranked relatively high in importance. Attention to the environment and social responsibility and sense leadership gap; "leadership gap"- 
Millennials who enter the boardroom and those in senior positions have a desire to rebalance business priorities by putting people before profit.

\subsection{Millennials Value Purpose Beyond Profit} Corporate values that are shared with and believed by Millennials also promote loyalty - particularly when employers demonstrate a strong sense of company purpose beyond financial success. Millennials intending to stay with their organizations for at least five years are far more likely than others to report a positive culture and focus on the needs of the individual. Those likely to remain longest share their organization's values, and are more satisfied with its sense of purpose and support of professional development.

\subsection{Relative Degree of Importance (Excluding Salary)}

On the other hand, they will find it hard to become an employer of choice if they attempt to differentiate primarily by means of their growth records, market leadership, use of technology or, least influential of all, the reputation of their senior executives. That said, should a leadership team bring its organization into disrepute, it is highly likely - given Millennials' values - that this will drive candidates away. This would be especially true of "super-connected" Millennials, who place a relatively large emphasis on the behavior of business leaders when measuring corporate success. This broad pattern of preference is observed across all markets, although some variation is seen. Millennials have control on their careers; Most survey respondents expressed satisfaction in this area-almost three in 10 (29 percent) say they have "total control" over their career paths. Adding the 48 percent who said they "have a large degree, but not complete control," more than three-quarters (77 percent) of Millennials feel their career paths are in their own hands and not influenced by others or outside events. Millennial parents ( 82 percent) feel more in control than those without children, as are those most engaged with social media ( 87 percent). Meanwhile, this sense of control is greater in more holistic organizations that generally try to do "the right thing." We, therefore, see Millennials expressing a greater sense of control if they work in organizations that support their ambitions, align with their values, feature collaborative and trustbased working cultures, and have a strong sense of purpose.

"Millennials want to feel in control of their careers and Millennials express a greater sense of control if they work in organizations that support their ambitions, align with their values, feature collaborative and trust-based working cultures, and have a strong sense of purpose. So, rather than hastening their exits, empowering Millennials might help retain them".

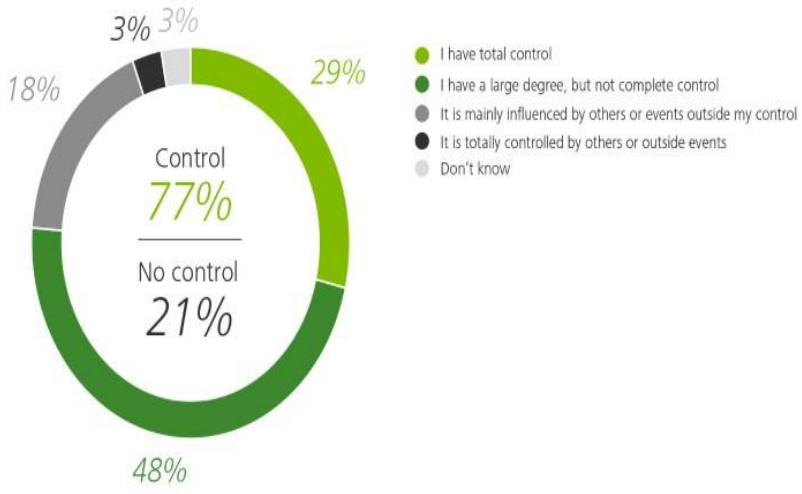

Figure 8; Source-PwC Study Report

\section{Projected population by generation}

In millions

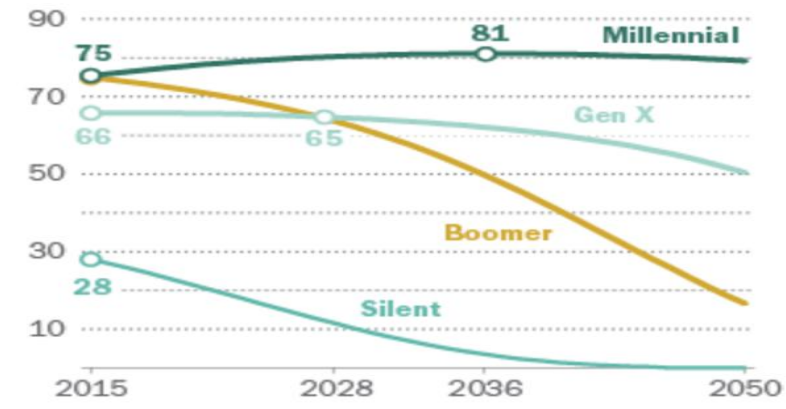

Note: Millennials refers to the population ages 18 to 34 as of 2015.

Source: Pew Research Center tabulations of U.S. Census Bureau population projections released December 2014 and 2015 population estimates

PEW RESEARCH CENTER

Figure 9: Source- PwC Study Report

\section{CONCLUSION}

Millenials evaluate everything including success in ways that go beyond a focus on financial performance, increasing the focus on activities and behaviors that support long-term sustainability. The potential for a "profits-first" approach and "leading organization," on its own will be a farce. 81 percent of the workforce in next decade will be the millennials and HR Strategists, Employers, Policy makers and Political stature will get the impact on everything under the sun. Millennials will be more interested in their professional development; and every innovation and zero distance in managing them will make a better future for mankind. 


\section{REFERENCES}

1. M., Debray, S. K., and Peterson, L. L. 1993. R Bedwell, W. L., \& Salas, E. (2010). Computer-based training: Capitalizing on lessons learned. International Journal of Training and Development, 14, 239-249.

2. Beekman, T. (2011). Fill in the generation gap. Strategic Finance, 93(3), 15-17. Blanchard, P. N., \& Thacker, J. W. (2010). Effective training: Systems, strategies, and practices (4th ed.).

3. Upper Saddle River, NJ: Pearson Education, Inc. Bohl, J. C. (2008). Generations $\mathrm{X}$ and $\mathrm{Y}$ in law school: Practical strategies for teaching the "MTV/Google" generation. Loyola Law Review, 54(4), 775-779.

4. Bunch. K. J. (2007). Training failure as a consequence of organizational culture. Human Resource Development Review, 6(2), 142-163.

5. Burke, L. A., \& Hutchins, H. M. (2007). Training transfer: An integrative literature review. Human Resource Development Review, 6(3), 263-296.

6. Conner, J. (2010). Generation GAP. Tire Business, 28(1), 1415. Donnison, S. (2010). Unpacking the millennials: A cautionary tale for teacher education. Australian Journal of Teacher Education, 32(3), 1-9. Elam, C.,

7. Stratton, T., \& Gibson, D. D. (2007). Welcoming a new generation to college: The Spring 2014 Volume 12, Number 1 Journal of Organizational Learning and Leadership 59 Millennial students. Journal of College Admission, 195, 2025. Feiertag, J. \& Berge, Z. L. (2008). Training generation N: How educators should approach the Net Generation. Education + Training, 50(6), 457-464.

8. Glass, A. (2007). Understanding generational differences for competitive success. Industrial and Commercial Training, 39(2), 98-103. Gorman, P., Nelson, T., \& Glassman, A. (2004). The millennial generation: A strategic opportunity. Organizational Analysis, 12(3), 255-270. Guillemette, M. (2009). And now a word from the millennials (as interpreted by a boomer). CPA Practice Management Forum, 5(7), 15.

9. Hershatter, A. \& Epstein, M. (2010). Millennials and the world of work: An organization and management perspective. Journal of Business Psychology, 25, 211-223. Johnson, S. D., \& Argon, S. R. (2003). An instructional strategy framework for online learning environments. New Directions for Adult and Continuing Education, 100, 31-43. Li, J., D’Souza, D., \& Du, Y. (2011). Exploring the contribution of virtual worlds to learning in organizations. Human Resource Development Review, 10(3), 264-285.

10. McGuire, D., \& Gubbins, C. (2010). The slow death of formal learning: A polemic. Human Resource Development Review, 9(3), 249-265. McWhorter, R. R. (2010). Exploring the emergence of virtual human resource development. Advances in Developing Human Resources, 12(6), 623-631.

11. Meister, J. C. \& Willyerd, K. (2010 May). Mentoring millennials. Harvard Business Review, 88(5), 68-72. Monaco,
M. \& Martin, M. (2007 April-June). The millennial student: A new generation of learners. Athletic Training Education Journal, 2. Noe, R. A. (2010). Employee Training and Development (5th ed.). New York, NY: McGraw Hill.

12. Partridge, H. \& Hallam, G. (2006). Educating the Millennial generation for evidence based information practice. Library Hi Tech, 24(3), 400-419.

13. Pritchard, K. (2008). Employee engagement in the UK: Meeting the challenge in the public sector. Development and Learning in Organizations, 22(6), 15-17. Shah, P. \& Hurt, A. C. (2014). A conceptual strategy for a differentiated employee experience throughout the employee lifecycle: Multigenerational perspective. In D. Chapman \& K. Guerdat Spring 2014 Volume 12, Number 1 Journal of Organizational Learning and Leadership 60 (Eds.), 2014 Academy of Human Resource Development International Conference in the Americans Proceedings. Houston, TX:

14. AHRD. Shaw, S. \& Fairhurst, D. (2008). Engaging a new generation of graduates. Education + Training, 50(5), 366378. Skiba, D. J. \& Barton, A. J. (2006 May). Adapting your teaching to accommodate the Net Generation of learners. OJIN: The Online Journal of Issues in Nursing, 11(2).

15. Small, G., \& Vorgan, G. (2008). iBrain: Surviving the technological alteration of the modern mind. New York, NY: HarperCollins Publishers.

16. Sujansky, J. (2009). Spoiled, impatient, \& entitled: Why you need strong millennials in your workplace. Supervision, 70(10), 8-10. Swanson, R. A. \& Holton, E. F. (2009). Foundations of Human Resource Development (2nd Ed.) San Francisco: Berrett-Koehler.

17. Twenge, J. M., Campbell, S. M., Hoffman, B. J., \& Lance, C. E. (2010 September). Generational differences in work values: Leisure and extrinsic values increasing, social and intrinsic values decreasing. Journal of Management, 36(5), 1117-1142.

18. Wesner, M. S. \& Miller, T. (2008). Boomers and millennials have much in common. Organization Development Journal, 26(3), 89-96. Wilson, M. \& Gerber, L. E. (2008). How generational theory can improve teaching: Strategies for working with the "millennials." Currents in Teaching and Learning, 